\title{
ARTICLE
}

\section{MORALITY AND ANIMALS}

During the last fifteen or twenty years, there have been a number of groups (somewhat misleadingly called "liberation movements") which have urged that the rights of women, blacks, and homosexuals have not been properly respected. Now these three have been joined by the animal 1iberation movement. In terms of the actual pain involved, the number of deaths, and even in terms of the amount of confinement, a good case can be made that animals are treated even worse than women, blacks and homosexuals. For example, in a single year in the United States alone at least sixty million animals are used as subjects for experimentation - most of whom are used (and usually killed) to test the safety of luxury products such as new cosmetics. Animals are subjected to confinement in factory farms where a hen, for example, is likely to be kept permanent1y in a cage in which it cannot even stretch its wings. Do human beings really have the right to kill animals so that we can eat their flesh - particularly when we bear in mind that feeding grain to animals before we eat them rather than eating the grain directly is an exceedingly inefficient way of feeding human beings?

The case of the animal libbers seems impressive but it has encountered determined opposition. In the matter of animal experiments it is objected that at least those cases where the experiments may lead to the prevention and cure of human allments, we should recognize that animal pain counts far less than human pain so that even if the experiments cause a greater total amount of suffering to animals than they prevent in human beings, they can still be perfectly justifiable. Some would even claim that it is justifiable to test new luxury goods, such as cosmetics, on animals. (The standard test is to inject increasing1y large amounts of the substance into a group of animals until half of them die, sometimes simply because of the volume of stuff that has been injected.) Their argument could start with the premise that while the interests of animals should be respected, whenever there is a conflict between the interests of animals and the interests of human beings, the interests of human beings should take precedence. If then it is in the interests of human beings to make the new cosmetics (consumers enjoy them, manufacturers make money and workers gain employment), it follows that, however painful the experiments may be for the animals they are st111 justifiable.

Or again it might be argued that we don't really know that animals are capable of feeling pain: after all, you can't feel an animal's pain so you can't be sure that it is suffering. In the matter of breeding animals to kill and use for meat, it has been argued that since they wouldn't have been born if a farmer hadn't planned eventually to use them for meat and since it is better to have even a short life than none at a11, raising animals for meat is, at the very least, unobjectionable, and in all probability commendable, even from the point of view of the animals themselves. Finally, it is sometimes claimed that animals are by their very nature incapable of having rights (although this claim is not quite as bleak as it appears for animal interests because those who make the clalm usually hold as well that it is wrong to do certain things to animals and that we even have obligations to do some things for them). 
human pain?

Almost all of us start out thinking that it is. I do not mean by this that we think (quite rightly) that there are kinds of mental suffering that human beings can undergo that animals can't. I mean rather that given what seem at least to be roughly equal amounts of human suffering and animal suffering, the human suffering strikes us as vastly more important. For example, if we learn that animals are being experimented on in order to test a new drug that may alleviate human suffering, we don't tend to worry about whether the chances are that more human suffering will be prevented than is being caused to the animals. If the experiments were to be conducted on human beings, however, we would react differently: we would probably not be willing to approve such experiments unless we supposed that they would prevent a great deal more suffering than they caused and even then, many of us wouldn't approve of it.

How could the view that animal pain is less important than human pain be defended? For most of us the initial response would be that because human beings are much more intelligent than animals, animal pain should count far less than human pain. It's not, we suppose, that we are playing favorites with our own species in the way that a racist favors his own race or a sexist favors his or her own sex. It is not that we have taken something that is morally neutral like sex or skin color and treated it as if it were morally relevant, thereby favoring our own kind just because they are our own kind. We think rather that we have observed a crucial difference between human beings and the other animals which it is appropriate to acknowledge by treating human suffering as far more important than animal suffering.

But is this what we are really doing? Are we simply recognizing a morally relevant difference between human beings and animals - that human beings are more intelligent than animals - adding the premise that the suffering of a less intelligent being counts less, and making the obvious deduction? If we really accepted this principle, we would treat the suffering of people of average intellect as in itself less important than the suffering of highly intelligent people, and the suffering of the retarded as even less important. But surely this would be wrong. Imagine having someone who is far more intelligent than yourself tell you that, because of your inferior intelligence, your pain should count less than his, or imagine someone suggesting that since some very retarded people seem less intelligent than some dogs upon whom we experiment, we should feel as free to experiment on such retarded human beings as we now do on dogs or guinea pigs or rats.

It might be argued that even though some human beings such as babies and some retarded persons are less intelligent than the most intelligent animals, human beings are characteristically more intelligent than animals and that this justifies treating babies and persons who are unusually retarded with far more concern for their pain than we would show if they were animals. But this argument still relies on the assumption that the pain of more intelligent creatures counts more heavily than that of less intelligent ones, an assumption whose full implications we are obviously unwilling to accept. Also, even if 
that were correct, why should we treat creatures who are not intelligent as though they were intelligent simply because they belong to a species most of whose other members are intelligent? It could be replied that we have a precedent for doing so in those insurance companies that treat young people who are unusually safe drivers for their age-group as though they were no safer than the average for their age-group. However, I think we would either regard this practice as unjustifiable or, if we find it justifiable, we do so only because the insurance companies claim that they lack sufficient evidence to determine which young drivers are the safe ones, and that collecting such evidence would cost too much to be feasible. But in the case of babies and the mentally retarded, there is no problem in determining their relative lack of intelligence.

Another argument for counting animal pain far less heavily than human pain is that we can be bound by agreements with other human beings not to cause them pain, but we cannot be bound by such agreements with animals because they can't make agreements. We could, however, be bound by agreements with animallovers not to inflict suffering on animals. More important, we quite properly feel that it is wrong to inflict suffering on other human beings even when we haven't agreed not to do so, either with them or with any other people. Suppose that you found an island inhabited by a tribe of people with whom neither you nor anyone in your society had made any agreements, that it was in your interest to do something that would cause them great distress, and that doing that thing would help you far less than it would harm them. Suppose that you proposed doing it and that someone protested that it would be wrong. It wouldn't do for you to reply that your proposed behavior would be perfectly all right because you were bound by no agreements with the tribe. Thus it would appear that you can have an obligation not to cause pain even if you aren't bound by an agreement not to do so, so this argument fails.

How do we know that animals can feel pain?

It might be argued that we needn't worry about causing animals pain because we don't know that they are capable of feeling pain, or indeed, that they have any experiences at al1. After all, the most you can do is hear an animal whimper or howl, or see it grimace or tremble or recoil or run away. You can't actually feel the animal's pain so you can't verify the claim that it is suffering; consequently, there is no need to act as if it is capable of suffering. But the same holds true of human beings. You can only see the outward signs of their suffering. You can only feel your own pain, not theirs; yet we don't believe that because of this it is morally acceptable to act as if other human beings never have painful experiences. But what justification do we have for supposing that other human beings have experiences more or less similar to our own? The most commonly employed argument is known as the argument from analogy for other minds. It is argued that in your own case you notice on innumerable occasions that certain kinds of behavior are associated with certain kinds of experiences, and that since you observe other people behaving in ways similar to your own, you are entitled to infer that they have experiences that are similar to your own. When you are burned, you feel pain and you engage in pain-behavior, e.g., 
you grimace, you flinch if the burn is touched, etc., so that it is reasonable to infer that when other people are burned and engage in painbehavior, they, too, feel pain. Further, the argument can be strengthened by determining that other people have nervous systems similar to your own.

An argument very like this can be used to show that animals have various kinds of feelings, particularly pain. They have similar nervous systems to ours, and when they are subjected to stimuli that we find painful, they typically engage in kinds of behavior analogous to our own: for example, cattle react to branding irons in much the same way in which we would react to branding irons.

This is a good point at which to answer a fairly common objection to vegetarianism. It is suggested that if we are to care about the feelings of animals, why shouldn't we care about the feelings of plants as well? But if we had to worry about the feelings of plants, we would have to give up eating them as we 11 as animals, and, if we did, we would die of starvation. But this line of reasoning assumes that we have good grounds for supposing that plants can have experiences and, in particular, painful experiences. Does the argument from analogy support this? I think not. It is dubious whether it makes sense to say that plants behave at all (unless you are using "behave" in a metaphorical sense), and even if it does make sense to say they behave, their behavior is too different from that of human beings to support the argument from analogy. Furthermore, plants don't have central nervous systems, and the evidence strongly suggests that pain is only felt when there is an effect on a central nervous system.

But even if plants can feel pain if they suffer when they are harvested, for instance - vegetarianism would still seem to be better than our present meat-eating practices because you don't need to harvest as much grain to feed people if you give it to them directly as you do if it is fed to animals and then eaten. You can feed a number of times as many people using grain directly as you can if you feed it to animals and then use them as meat. 1 Many philosophers don't think that the argument from analogy is successful, 2 and they give alternative justifications for the claim that other human beings have minds. These other justifications, however, would seem to work as well to show that animals have minds as they do to show that other human beings do.

Are experiments ever justifiable without the subject's consent?

If there is no good reason for regarding animal suffering as less important than human suffering, a minimum requirement for the justification of an animal experiment is that it either (1) be reasonable to expect that the experiment will cause less suffering than it will prevent; or (2) that, even if it is likely that the particular experiment will fail, the enormous gain in preventing future suffering that would be made if it were successful makes the gamble worthwhile even when the animal suffering caused by the experiment is taken into account. This requirement would almost certainly eliminate most animal experiments, but there would clearly remain a considerable number of experiments in which it would be reasonable to suppose that the requirement would be sat1sfled. Are any other requirements in order? 
In the case of human beings, it is sometimes regarded as obvious that no human being should ever be experimented on without his own consent. This may not be as obvious as it seems, but for the time being let's accept it. In the case of human beings, one can sometimes get consent by offering a reward that will lead the subject to accept the risk and distress of the experiment, and there are also some people who will consent for idealistic reasons, who are willing to make a personal sacrifice in the hope of preventing or alleviating the suffering of others. But in the case of animals, getting consent is out of the question: you can't explain the dangers to them, you can't explain the object of the experiment, and you can't tell them about the reward you propose to give them. And if none of these things can be explained to an anima1, it obvious1y isn't going to consent. Does this mean that all experiments on animals are morally wrong, even those that make sense when the suffering of all sentient beings is taken into account?

Consider the matter of rewards. If a child is unable to understand the possible reward for taking a certain risk or for undergoing certain suffering, we sometimes feel justified in forcing him to do so because it is for his or her own good. If, for example, a child needs a painful operation, we may feel entitled to perform it without his or her consent provided we are in a better position to determine what is in the child's long-term interests than he or she is. Could a similar situation arise with animals? In the case of the child, the good things come after the bad thing (the operation) rather than before it. This condition can't be met for an animal if the experiment will result in its death. Still, not all animal experiments are expected to end in death; sometimes there is no danger of death, and sometimes the danger is low enough so that it would be reasonable for an animal to take the risk involved, provided an adequate reward were given afterwards. In such cases, there could be moral grounds for conducting the animal experiment without its consent which were as good as those for performing the operation on the child. It is, of course, more difficult to think of rewards for animals than for human beings. For human beings it is easy: most of us want a great many things that money can buy. Still, even though it is hard to think of adequate rewards for animals, it should be possible with a bit of ingenuity. For example, if you captured an animal in a place that provided a poor environment for it because the food supply was inadequate, or because it didn't provide the animal with an opportunity to engage in some of its natural activities, you could as a reward move it after the experiment to a more suitable environment. Or if an animal was likely to be exposed to a certain disease, the reward could be an inoculation against it. If the experiment wasn't very risky, the animal's prospects for survival might be better with the whole package involving the risk of the experiment and the protection of the inoculation than they would be without it.

But in the case of many experiments, the animal is 1ikely to die or to be so much worse off because of the effects of the experiment that nothing you could do for him after the experiment would leave him as we11 off then as he would have been if you had left him alone. If we felt that such experiments could never be conducted, we would be barred from performing many experiments that can be expected to prevent a great deal more suffering than they would cause, so this is a 
matter that deserves careful consideration. An important thing to note is that most animals that are subjected to experiments are bred for that very purpose. If it were not for the animal breeders, the parents of the future subjects of experiments would not have mated with one another, or at the very least, would have mated at different times. For this reason the animals destined to be subjects of many, and perhaps most, fatal experiments would not have existed at all if someone hadn't planned to perform those experiments. A large portion of animals now raised for experiments would have been better off if they had never been born. But this could be changed. It is possible to raise animals to be used for experiments in such a way that their lives as a whole, though shorter than the normal life of an animal of their species, would be better than no life at all. Insisting on such a requirement would, of course, make such experiments a good deal more expensive but from the point of view of those of us who stand to benefit from such experiments, that would be much better than banning them altogether. There is the further advantage that it would give experimenters a financial incentive to think twice before subjecting animals to fatal experiments.

Would such an arrangement really provide us with a satisfactory way out of the moral dilemma with which we seemed to be confronted? Would it enable us to carry on those experiments that make sense in terms of the overall goal of decreasing the suffering of sentient beings without infringing on what might be taken to be a basic right - the right to protection from experiments that could not be made part of a package that it would be reasonable for the subject to accept? The argument in favor of the experimenter would be that in glving the animal a good life before the experiment (when it wouldn't otherwise have had any life at a11), he is conferring a benefit that outweighs the harm that comes later. It might be objected that you aren't benefiting an animal when you give it $11 \mathrm{fe}$, even if the $11 \mathrm{fe}$ is on the whole worth living. But why not? Surely it makes sense to say that you are glad that you were born? And it won't do to object that it doesn't make sense to compare existence with non-existence, because it does make sense to compare being alive with being dead and to express a strong preference for being alive. It might be objected, too, that it is wrong to bring something into the world under a sentence of death. But we are all under sentence of death: we are all mortal. The objection can be re-stated: 1 t is wrong to bring anything into the world under sentence of an unnatural death. It can also be argued that the experimenter was guilty of "speciesism" in that he was prepared to do something to animals that he would not be willing to do to human beings. Clearly we wouldn't be willing to bring human beings into the world to serve as subjects of fatal experiments. Are we guilty of speciesism then if we are willing to do this to animals?

I belleve that in this case we are not because there are a number of morally relevant differences. First of all, if we had such a practice regarding adult human beings or even relatively young children, the people who were to serve as subjects for such experiments would know what was in store for them whereas animals do not and are therefore spared the mental anguish human beings would suffer in anticipation. Secondly, although $I$ have argued that animal 
pain is not less important than that of human beings, this is perfectly compatible with holding that it is far more important to preserve the lives of human beings than the lives of animals because human beings characteristically have far richer lives than animals. Thirdly, because it is more important to preserve human and animal lives, it is desirable for us to have particularly strong feelings of revulsion towards the killing of innocent human beings. 3

Two final points should be made. First, it is important to determine whether animal experiments involving suffering or death are always wrong, or whether at least a small fraction of them are justifiable because it is almost certain that if one bars all such experiments, at least some discoveries that would prevent more suffering than is caused to the animal in terms of the overall goal of minimizing suffering for all sentient beings will be blocked. If one grants that animal experimentation (even that which results in the animal's death) may be justifiable where it would prevent more suffering than the experiment causes, one is no longer open to the most plausible objection of those who support our present laboratory practices. Secondly, it is now possible to obtain much of the information that has hitherto been gained from experimenting on animals by alternative techniques which are not only more accurate and reliable but frequently less expensive. Obviously these developments should be publicized, particularly because the large industry which has developed for breeding experimental animals has a natural interest in opposing the use of alternative techniques.

Do the interests of human beings always take precedence over the interests of animals?

It has been claimed that although the interests of animals should be respected, the answer to this question is obviously "yes". On first glance, this seems eminently reasonable. 4 After a11, it is admitted that the interests of animals should be respected and surely it is no more than commonsense to suppose that when there is a conflict between the interests of human beings and animals, the interests of human beings should take precedence. And think of the advantages to be gained from recognizing this. In the preceding discussion of animal experiments, it was argued that experiments designed to test the safety of new luxury goods such as cosmetics should be abandoned, that we should simply give up those luxury goods. But that would mean not merely that some women would have to do without certain new cosmetics, it would also mean that people wouldn't be employed making and selling them. But if it is agreed that the interests of human beings should always take precedence over the interests of animals, women could have new cosmetics and cosmetic-workers their jobs. But can we really accept the principle that whenever there is a conflict between human and animal interests, human interests should prevail, no matter how much animal suffering would be required? Consider the tasty liverpaste known as paté de foie gras. In order to make it, geese are forcefed until their livers burst. Or consider boiled crabs and lobsters. The common practice is to place them, still alive, in boiling water, and there is good evidence now available to show that they do not die instantaneously or painlessly, but go on suffering for several minutes. (Putting them in tepid water and 
bringing it slowly to boil does not help; it prolongs the process.) In both these cases our present practices serve the interest of human beings so the principle of giving human interests precedence is forced to sanction them. The obvious conclusion is that the principle is wrong.

Would animals be worse off in a world of vegetarians?

Consider the following rhetorical question: "If everyone became a vegetarian, would there still be any sheep or cattle in the world, well cared for and guarded against starvation?" The obvious answer is that probably very few of them would exist unless they were kept as pets. Left to themselves, they would be hard put to it to survive. Furthermore, even if some sheep and cattle would exist in a vegetarian world, a great many more who would have been raised for food in a meat-eating world would never be born.

Now suppose that these animals that would never be born in a vegetarian world had been born and were given lives that were worth living before they were killed for meat. Isn't it better that they should have been born and given shortened lives than that they should have no life at all? If this is so, then isn't it better, even from the point of view of the animals who will eventually be eaten, that the world should not become vegetarian? Isn't it in fact wrong to encourage vegetarianism because, insofar as you are successful, you will prevent the existence of animals who would otherwise be born and live relatively happy (although shortened) lives?

There are two main objections to this. First, the argument rests on the supposition that animals raised for meat are characteristically given relatively happy lives and, in a world in which factory-farming is increasingly common, that supposition is debatable, to say the least. Secondly, the argument rests on the supposition that it is wrong (or at least prima facie wrong) to prevent the existence of beings that would have happy lives. Holding this view does not require you to hold that it is always wrong to practise birth control or even that it is always wrong to have an abortion because there might be countervailing factors that make abortion or birth control acceptable or even obligatory. In an overpopulated world, such countervalling factors are increasingly likely to be present. Overpopulation also provides a reason for not raising animals for meat because when you do so you get only a fraction as much food value from the meat as you would get if the grain needed to raise the animal had been given directly to human beings.

Because of the last consideration alone, it seems that even if it is prima facie wrong to encourage vegetarianism (thereby preventing the existence of relatively happy animals), when everything is taken into consideration it may not be wrong on the whole to do so, and it may even be obligatory. Still the question remains as to whether it is at least prima facie wrong to prevent the existence of animals who would have relatively happy lives. In considering this question, it will be useful to construct an imaginary case in which the claim that it would be wrong to prevent the existence of animals even though they are eventually to be killed will be made as strong as possible. Let's suppose, first, that there is no food shortage so that we can ignore the claim that grain used to feed animals should be given instead directly to human beings. Let's confine ourselves to 
those animals who couldn't survive on their own, and 1et's suppose that instead of raising them on factory farms, they are given an idyllic existence. Let's suppose further that the only way in which it is commercially feasible to raise them is for food. Imagine that a reformer makes the proposal that these animals are not to be killed for meat but that, since society cannot afford to take care of them, they be allowed to fend for themselves. Clearly, this would not be in the animals' interest (since the case stipulates that they cannot survive on their own), whereas if they were not set free, most of them would enjoy many more years of an agreeable life (even though they had to die at the end of it).

Now suppose instead that a farmer proposes that he breed some pigs, and that he agrees to give them a good life and as humane a death as he can contrive, provided he is allowed to butcher them eventua11y. It is hard to see why even someone particularly concerned with the pigs' welfare should oppose his plan. After all, this batch of pigs will not be born if they aren't meant to be butchered. Wouldn't the pigs, once they were born, be glad (if they could understand the situation) that they had been born even if a necessary condition for their life is eventual death? After all, we are all going to die, and most of us will die much worse deaths than these animals.

Still, it might be replied that in order for it to be wrong to prevent the birth of someone, you must have an obligation to him, and you can't have an obligation to a nonexistent being. But consider the following case. Because a prospective mother has an abnormal condition, any child she conceives who is allowed to be born will have a wretched life. Such a person would surely have an obligation to prevent the conception of such a child. Surely it would be wrong to conceive it, and wrong, if it were conceived, to allow it to be born. This seems to show either that we can have obligations to non-existent beings or, at the very least, that it can be wrong to do certain things because of their effects on non-existent beings. it is objected that what makes the conception wrong is not the baby's suffering but the trouble it will cause others, the example could be changed by specifying that the child's case be of medical interest; this benefit to others will offset the trouble to them so that in this case conceiving the child would be wrong only because of that child's suffering.)

Consider the following argument:

1. It is morally bad per se to add miserable creatures to the world.

2. Suppose that it is not morally good per se to add happy creatures to the world.

3 . Then it is not morally permissible to add a group of creatures to the world (taking only the group's welfare into account) if some members of the group are miserable, no matter how many are happy.

4. But it is permissible to add such a group (taking only their welfare into account) if enough of them will be happy.

5. Therefore it is morally good per se to add happy creatures to the world.

A number of objections have been raised to this argument. (I should say before describing the controversy that it has been carried on in terms of people rather than the broader 
category including animals as well and I will describe it in terms of people, but the arguments apply equally well to animals.) Bennett claims that we don't need the happiness of the happy offspring to balance against the unhappiness of the miserable ones; that we can use instead the anticipated gain in happiness for the parents.5 Bennett raised this objection against a version of the argument in which it was not as apparent as it is in the present version that only the interests of those added to the world are taken into consideration. Clearly his objection wouldn't work against this version. 6 William Anglim suggests on the other hand that the argument only shows that it is a supererogatory good deed to add happy creatures to the world. 7 Anglim raised this objection within a utilitarian framework, and I responded ${ }^{8}$ that within such a framework it wouldn't count as supererogatory to add happy people to the world unless doing so is good in itself. For a utilitarian, an action couldn't be supererogatory unless it had a good consequence. It would be supererogatory because it demanded an undue amount of sacrifice from the agent in comparison with the value of the consequence for others; rather than because it was not a good thing to bring about that sort of consequence. Michael Bayles misinterprets the argument taking its conclusion to be that we can have obligations concerning possible persons and objects that the premiss to the effect that it is morally bad to make possible miserable persons actual assumes the consequent. 9 But the argument is directed to philosophers who, like Bayles himself, suppose that it is a bad thing to make miserable possible persons actual. A philosopher who rejected that premiss would suppose that the argument was unsound but it's a difficult premiss to reject.

I know of no successful refutation to this argument. $10 \mathrm{Still}$, the overall argument against vegetarianism would not succeed unless it could be shown that the majority of animals bred for food would probably be given happy lives, and this seems unlikely. Furthermore, it is very difficult in an overpopulated world in which many people are starving to justify feeding animals to make them into food, when giving grain directly to human beings would feed several times as many as could be fed with the slaughtered animals. The opponent of vegetarianism may succeed in showing that vegetarianism is prima facie wrong because it would prevent the existence of some happy animals. However, that is not enough to show that it is wrong on the whole because it would probably also prevent the births of a much larger number of unhappy animals. Finally, even if he should satisfy us as to the welfare of animals, he would still have to convince us that the overall benefit to animals would exceed the harm done to human beings by producing food in an extremely inefficient way when millions of people are starving.

\section{Can animals have rights?}

Some people suppose that not only do animals lack certain rights, but they are incapable of having any rights at all. Most of these people would nevertheless think that we have an obligation not to do certain things to animals (such as torturing them) and many of them would hold that we have obligations to do certain things for animals. This is important because having rights is only an advantage insofar as it gives others the obligation to do certain things for you and to refrain from doing 
certain other things to you. For instance, there would be no advantage in having the right to freedom of speech in religious matters if no one had an obligation to refrain from preventing you from speaking about your religious beliefs. Or, to take another example, there would be no advantages for Canadians in having the right to freedom from hunger unless some other people had (or in some situation would have) an obligation to provide needy Canadians with food.

It is commonly felt that certain rights should be respected no matter what the circumstances, e.g., the right never to be punished when you are innocent or the right never to be tortured. There are many people who would feel however that, in extreme circumstances, even such basic rights as these may be violated. (Mightn't it be justifiable, for example, to torture one person if the only alternative was letting a great many people be tortured?)

There are also rights that most of us would agree can be overridden in abnormal situation: for example, the right to be told the truth or the right to have promises kept. And finally, there are rights that are fairly commonly overridden, such as the right to an advanced education for those who are sufficiently talented to benefit by it. In a society that is not particularly affluent, the obligation of the state to provide such an education for some citizens may be overridden by its obligation to provide for the more basic needs of other citizens. It is important to remember that there are these weaker sorts of rights as we11 as (possibly) the strongest sort of right (those which can never be overridden) because even if one doesn't grant that animals can have the strongest sort of right, it doesn't follow that they have no rights at a11.

Turning back to the relation between rights and obligations towards those who have rights, imagine two people who agree on what obligations we have to animals (what things we have obligations to do for them, and what things we have obligations not to do to them), but who disagree on whether animals have rights or not. For an animal concerned with his own welfare, it wouldn't matter which of these two positions is taken. Or suppose that Jones thinks that we have more obligations towards animals than Smith does, but that Smith believes that animals have rights while Jones does not. An animal with an eye to his own interest would prefer to have people believe what Jones does, despite the fact that he thinks animals have no rights. More concretely, suppose that Jones thinks that even though animals have no rights, we should never kill or torture them while Smith thinks that animals have a right not to be tortured but that it is permissible to kill them. A friend of animals would be well-advised to prefer Jones' view, the no-rights view, because the consequences of accepting Smith's view would obviously be far worse for animals. I myself believe that where there are rights there are corresponding obligations, and, conversely, that where there are obligations there are corresponding rights (though this requires defense which is beyond the scope of this paper.) At any rate, the crucial thing for animal welfare is that we have some obligations to them.

Some philosophers who think that animals have no rights but that we have obligations to them think that these obligations are based on the fact that animals have interests. Although I disagree with the claim 
that animals lack rights, this theory does at least allow for the proper treatment of animals. Others who think that animals have no rights think that our obligations towards them are based, not on their interests but (1) on agreements with other human beings (and, further, that agreements are the only source of rights and obligations); or (2) on the need to preserve our own good character.

Theory (1) grounds a11 rights and obligations on agreements: in order to have a right, you must either have made an agreement giving you that right, or you must at least be capable of making such an agreement. An objectionable consequence of (1) is that it leaves not only animals but babies and the insane with no rights. Even so, since we can still have obligations towards them, it is perhaps enough. But there is still an unacceptable consequence of (1). Suppose that in a given society no one cared about the welfare of the insane or infants, and that there was no agreement, for example, that they should not be tortured. It would follow that in that society it would not merely not be regarded as wrong to torture babies and the insane, it wouldn't be wrong.

As for view (2), that we have obligations towards animals because treating them bad1y is injurious to one's character rather than because it is injurious to animals, the claim would seem to be that one won't have the sort of character that will lead to treating human beings well unless one has the sort of character that leads to treating animals well. But this is surely false: many people who have been models of virtue in their treatment of other human beings have done or allowed others to do dreadful things to animals. One can unfortunately be virtuous towards the members of some in-group while giving no thought to the members of an out-group. (This is, of course, also a problem for the dealings of human beings with each other, and an important kind of moral progress consists in making the boundaries of what one takes to be the in-group broader and broader - to include not only one's family, one's town, one's country, al1 mankind, but, for animal liberation, to include all sentient beings.)

\section{Why should I become a vegetarian?}

Some readers may feel that while it would be desirable for our society as a whole to become vegetarian, nothing can be gained by particular individuals becoming vegetarian so that they personally have no obligation to do so. A similar argument could have been given to defend the owning of slaves, and, if everyone had accepted it, the institution of slavery would almost certainly have survived. It's theoretically possible, of course, that people who took advantage of slavery while it existed would still have voted for its abolition. Still, it is unlikely that a society of slave-owners would vote for the abolition of slavery, and the same holds for a society of meat-eaters and the abolition of raising animals for meat. Furthermore, if in becoming a vegetarian you show that a vegetarian can have a healthy and enjoyable diet, your example tends to encourage others. And the more vegetarians there are, the easier it is to be one because they create a demand for vegetarian restaurants and grocery stores. Also, when people act in accord with certain moral beliefs, they characteristically become more deeply committed to those beliefs. In the case of animal rights, it is particularly important that we should be deeply concerned because, un1ike homosexuals or women or racial minorities, animals are 
dumb: they literally cannot speak for their own rights and so we should speak for them.

\author{
R. I. Sikora \\ University of \\ British Columbia
}

1 Cf. Peter Singer's Anima1 Liberation (New York Review Books, New York, 1975.)

2 I believe myself that it does at least show that other creatures have experiences, as I've argued in "The Argument from Analogy is not an Argument for Other Minds," American Philosophical Quarterly, April, 1977. An additional argument is needed to show that the same mind is associated with a given body throughout its entire existence.

\section{Although I think that the} basic rationale for an ethical system should be utilitarian, I agree with Brandt in holding that a society whose members were guided by a pluralistic code selected on the basis of utilitarian considerations would be much happier than one whose members endeavored to follow act utilitarianism. The two main reasons for this are that it would be very difficult to predict the behavior of other people in an act utilitarian society because it would be very difficult to determine which actions they would think of as maximizing utility, and that it would be far easier to rationalize in one's own favor if one were guided by an act utilitarian code than if one were guided by the right sort of pluralistic code. I also agree with Brandt in thinking that it is important for us to have strong feelings of revulsion associated with the violation of some of the more important parts of such a code.
For further discussion of this view, cf. Richard Brandt: A Theory of the Good and the Right (C1arendon Press, Oxford, 1979) chapter 15.

4 Kai Nielson takes this view in "Some Puzzles about Formulating Ut1litarianism," Ratio, Vol. XV, no. 2, pp. 256-62. I attack it in "Towards a Satisfactory Formulation of Utilitarianism," Ratio, XIX, no. 1, pp. 68-9.

5 Jonathan Bennett, "On Maximizing Happiness," in Obligation to Future Generations, edited by R. I, Sikora and Brian Barry, Temple University Press, Philadelphia, 1978, pp. 61-73.

\section{Sikora, "Is It Wrong to Pre-} vent the Existence of Future Generations?", from the same anthology, p. 112-166.

\section{William Anglim, "Repugnant} Conclusion," Canadian Journal of Philosophy (1977), pp. 145-54.

8 Sikora, "Utilitarianism, Supererogation and Future Generations," Canadian Journal of Philosophy, September, 1979.

9 Michael Bayles, Morality and Population Policy, University of Indiana Press, 1980.

${ }^{10}$ There is, however, a counterargument which is worthy of serious attention. If it's a good thing to add people with a positive happiness level to the world even if their happiness level is barely positive and people already here should therefore be prepared to make sacrifices to do so, it would be possible in theory at any rate for them to be required to go on making sacrifices till the world declined from a high happiness average to one that was barely above neutrality. But such a 
world would be inferior to the world with which they began so the view that it is a good thing to add happy people to the world must be mistaken. The view that we should aim at a world with the highest possible average level of happiness avoids the objectionable conclusion (Derek Parfit calls it "the repugnant conclusion") but it has the grossly counterintuitive consequence that under certain circumstances it would be wrong to add happy people to the world even if doing so would raise the happiness level of all those already there. I have argued that all other views that are at all plausible have a consequence that is closely analagous to the repugnant conclusion and that is, if anything, more objectionable than it is. McMahan questions this analogy in his review of Obligations to Future Generations in the October 1981 issue of Ethics to which I respond in the same issue. The main theme of my argument is that if it isn't a good thing to add happy people to the world and if there were a few people with a very low leve1 of happiness in the world who could either help each other to be a bit better off or bring about a new race of very happy people, they should do the former rather than the latter and thus leave us with a miserable world rather than a happy one. It is unfortunately impossible to develop this response properly without devoting more space to it. I have attempted here to briefly suggest the lines of present controversy which, although they have been carried on specifically in terms of people apply equally well. to animals.

SUA

INSTRUC'IONS FOR AUTIIORS

All material submitted for publication in Etlics \& Animalg should be addreased to the Editor. Reviews and articles should be typed. On one slde of the paper only. One copy is sufficlent for all submisstons except articles, of which three coples are requested. To facl]ltate 'blind' reviewing of articles the author's name should not appear on. the manuscript, but should be on a separate sheet of paper which also bears the title of the article. If possible, authors should also remove internal references which would Identify them (such as "as I argued in my article on animal liberation in "lhe Journal of Beasts"). Such references can be re-inserted before publication. 